Homepage: http://epubs.icar.org.in/ejournal/index.php/JWR

\title{
Variability in phytic acid and phytase levels and utilization of synthetic hexaploids for enhancing phytase levels in bread wheat
}

\author{
Amit Vashishth ${ }^{1}$, Sewa Ram ${ }^{1 *}$ and Vikas Beniwal ${ }^{2}$ \\ ${ }^{1}$ ICAR-Indian Institute of Wheat and Barley Research, Karnal, Haryana, India \\ ${ }^{2}$ Maharishi Markandeshwar University, Mullana, Ambala, Haryana, India
}

\section{Article history}

Received: $12-02-2017$

Revised : 26-04-2017

Accepted: 15-05-2017

\section{Citation}

Vashishth A, S Ram and V Beniwal. 2017. Variability in phytic acid and phytase levels and utilization of synthetic hexaploids for enhancing phytase levels in bread wheat. Journal of Wheat Research 9(1): 42-46. doi.org/10.25174/2249$4065 / 2017 / 69945$

*Corresponding author Email: sewaram01@yahoo.com

\begin{abstract}
Phytic acid and phytase levels in wheat grains have greater influence on the bioavailability of micronutrients to human beings. Hence in the present investigation, two hundred fifty seven wheat genotypes including 168 synthetic hexaploids and 89 wheat cultivars were used to assess variability in phytase and phytic acid levels. The phytic acid content showed 1.5 fold variations from 1.03 to $1.58 \%$ with the mean value of $1.34 \%$ in bread wheat cultivars while higher variability (2.1 fold)was exhibited in synthetic hexaploids ranging from 0.93 to $1.98 \%$ with the mean value of $1.35 \%$. There were 4.1 fold differences in phytase levels in wheat cultivars varying from 284 to 1155 FTU/ $\mathrm{Kg}$ with the mean value of $516 \mathrm{FTU} / \mathrm{Kg}$ and 7.9 fold in synthetic hexaploids varying from 255 to $2025 \mathrm{FTU} / \mathrm{Kg}$ with the mean value of $751 \mathrm{FTU} / \mathrm{Kg}$. There was very strong correlation $\left(\mathbf{R}^{2}=0.89\right)$ in phytase levels between duplicate samples of the wheat flours demonstrating high reproducibility of direct assay method used in this investigation. The method has additional advantage of analysing small quantity of materials available in the segregating generations of breeding programme.The selected synthetic hexaploids having high phytase levels are useful source for improving phytase levels in bread wheat cultivars.
\end{abstract}

Keywords: Agrobacterium, phytase, phytic acid,wheat, micronutrients, synthetic hexaploids

\section{Introduction}

Wheat (Triticum aestivum L.) is the main source of world's food energy and contains significant amount ofcarbohydrates, minerals, fat, vitamins and proteins essential for human health (Piironen et al., 2009). However, the absorption of essential micronutrients such as Fe and $\mathrm{Zn}$ is strongly inhibited in the human gastrointestinal tract by the presence of anti-nutritional element known as phytic acid (Greiner and Konietzny, 2006). Phytic acid,(myo-inositol 1, 2, 3, 4, 5, 6-hexakisphosphate; InsP6) also known as phytate, contains more than $80 \%$ of the total phosphorus in the grain. The negatively charged phosphate group in phytate strongly binds to divalent cations such as $\mathrm{Ca}^{2+}, \mathrm{Fe}^{2+}, \mathrm{K}^{2+}, \mathrm{Mg}^{2+}$ and $\mathrm{Zn}^{2+}$ at physiological $\mathrm{pH}$ to form a mixed salt called phytin which reduces the bio-availability of micronutrients to humans and monogastric animals (Greiner and Konietzny, 2006). This leads to Fe and $\mathrm{Zn}$ deficiency in human population making them prone to several diseases (Guo et al., 2012). This problem is more common in infants and pregnant women who require relatively more quantity of micronutrients.In addition, some monogastric animals are not able to metabolize phytic acid due to the lack of sufficient level of phytate hydrolysing enzymes activity in their digestive tract and as a result the feed of these animals are enriched with phosphorus. Large amounts of phosphorus, micronutrients and phytic acid (PA) are excreted through faecal material and gets accumulated in the water and causes algal blooming and phosphorus 
pollution (Brinch-Pedersen et al., 2002). Therefore, the hydrolysis of phytic acid present in the grain is needed to solve the problem of micronutrient deficiency in human beings and monogastric animals.

The hydrolysis of phytic acid can be accomplished either by addition of isolated phytases to the production process and the use of recombinant food-grade microorganisms as carriers for phytate-degrading activity in the human gastrointestinal tract or using wheat varieties high in phytase levels. Dietary phytases are important sources of phytate breakdown in human intestine (Sandberg and Andersson, 1998). Lopez et al. (2003) also reported that varieties had major influence on mineral bioavailability in which improved break down of phytate was related to higher phytase levels. Phytase (myo-inositol hexakisphosphatephosphohydrolase; EC 3.1.3.8) is a subgroup of phosphatases which enables to start the sequential dephosphorylation of phytate in cereals. Development of wheat with higher phytate degrading activity may result in more extensive phytate degradation in human stomach and improved micronutrient bioavailability. However, there are limited reports on phytase variability in wheat (Kim et al., 2002; Liu et al., 2007; Ram et al., 2010). Therefore, it is needed to see the variability in phytic acid and phytase levels occurring naturally in diverse wheat genotypes. In the present investigation, variability of phytic acid and phytase levels were evaluated for 168 synthetic hexaploids and 89 wheat varieties. The information was used in crossing of high phytase synthetic hexaploid lines (Synthetic 70) with high yielding wheat varieties (PBW343) and generating back cross populations.

\section{Materials and methods}

2.1 Plant material: A set of 168 synthetic hexaploids procured from CIMMYT, Mexico and 89 wheat varieties developed in India were grown and analysed at Indian Institute of Wheat and Barley Research, Karnal, India during 2014-15 and 2015-16 for phytase and phytic acid levels. Backcross population of a cross between PBW 343 and Syn70 was developed and analysed for phytase activity to enhance phytase levels in the background of PBW 343. The wheat grain samples were grounded with the Cyclotec Mill and passed through a $0.05 \mathrm{~mm}$ sieve and stored at $4^{\circ} \mathrm{C}$ for the measurement of phytase levels and phytic acid content.
2.2 Determination of phytic acid: Phytate content was determined by the modified method of Lorenz et al. (2007), Gao et al. (2007) and Ram et al. (2010). $80 \mathrm{mg}$ of the whole meal flour was weighed and mixed with 1.6 mlof $0.65 \mathrm{~N}$ $\mathrm{HCl}$ in $2 \mathrm{ml}$ micro-centrifuge tubes and shaken overnight at room temperature followed by centrifugation at 10,000 $\mathrm{g}$ for $20 \mathrm{~min}$. Wade reagent was prepared for final reaction by using 5 -sulfosalicylic acid and ferric chloride as per (Lorenz et al., 2007) and diluted 5 times.The absorbance was taken at $490 \mathrm{~nm}$. The sodium phytate salt (Sigma) was used for preparing standard curve for phytic acid content. The phytic acid content was expressed in percentage on dry weight basis.

2.3 Phytase assay: Phytase levels were measured using modified methodologies (Kim and Lei, 2005; OkotKotber et al., 2003 and Ram et al., 2010). $100 \mathrm{mg}$ of the whole meal flour was soaked overnight in $1.0 \mathrm{ml}$ of $50 \mathrm{mM}$ sodium acetate buffer ( $\mathrm{pH} 5.3$ ) in $2.0 \mathrm{ml}$ tubes at $4^{\circ} \mathrm{C}$ and centrifuged at $12,000 \mathrm{rpm}$ for $30 \mathrm{~min}$. at $4^{\circ} \mathrm{C} .0 .2 \mathrm{ml}$ of the supernatant was used in enzyme assay.Two hundred microliter of $0.5 \%$ (wt $/ \mathrm{vol}$ ) sodium phytate was added in each tube and incubated at $50^{\circ} \mathrm{C}$ for $30 \mathrm{~min}$. for enzymatic hydrolysis. The reaction was stopped by adding $0.4 \mathrm{ml}$ of absolute trichloroacetic acid at room temperature. The control reaction was set by adding TCA before the enzyme to inhibit its activity. The mixture was centrifuged at $10,000 \mathrm{~g}$ for $30 \mathrm{~min}$. and $0.2 \mathrm{ml}$ of supernatant fraction was mixed with $1.8 \mathrm{ml}$ of distilled water and $2 \mathrm{ml}$ of fresh colour reagent and incubated at $50^{\circ} \mathrm{C}$ for $15 \mathrm{~min}$. The colour reagent was prepared by mixing three volumes of 1 Msulphuric acid, one volume of $2.5 \%$ ammonium molybdate and one volume of $10 \%$ ascorbic acid (wt/ vol). Series of diluted potassium phosphate solutions were used as standards (Ullah, 1988). The absorbance of each reaction mixture was taken at $820 \mathrm{~nm}$ and the enzyme activity calculated. One unit of phytase is defined as the amount of enzyme required to release $1 \mu \mathrm{mol}$ of inorganic $\mathrm{P} / \mathrm{min}$ from sodium phytate at $50^{\circ} \mathrm{C}$. The phytase activity was calculated in FTU/kg on dry weight basis.

2.4 Statistical analysis: The analysis was carried out by ANOVA for both traits to test the level of significance. The ANOVA was performed from SAS PROG GLM statistical tools by using linear model.The data were expressed as mean $\pm \operatorname{SE}(n=3)$. The reproducibility of the method was tested by regression analysis. 


\section{Result and discussion}

3.1 Variations in phytic acid content: In order to determine genotypic differences in phytic acid levels, 257 wheat genotypes including 168 synthetic hexaploids and 89 wheat cultivars released in India were used in the present investigation. The phytic acid content showed 1.5 fold variations from 1.03 to $1.58 \%$ with the mean value of $1.34 \%$ (Fig. 1). It exhibited higher variability (2.1 fold) in synthetic hexaploids ranging from 0.93 to $1.98 \%$ with the mean value of $1.35 \%$. Different range of phytate levels have been reported by several workers (Lopez et al., 2003; Dost and Tokul, 2006; Steiner et al., 2007; Liu et al., 2007; Ficcoet al., 2009) depending on the germplasm and different assay procedures used. The analysis of variance showed significant differences among genotypes for phytic acid content and indicated potential for genetic improvement in wheat for low phytic acid (Table 1). Thus the data demonstrated that wheat germplasm with low phytic acid is available for utilization in breeding to improve high yielding varieties for micronutrient bioavailability.

Table 1. Analysis of variance (ANOVA) of phytic acid in the grains of 168 synthetic hexaploids

\begin{tabular}{lllll}
\hline Source & SS & df & MS & F \\
\hline Genotypes & 17.43 & 167 & 0.104 & $58.284^{* *}$ \\
Replication & 0.01 & 2 & 0.015 & 8.933 \\
Error & 0.299 & 167 & 0.001 & \\
Total & 17.74 & 336 & & \\
\hline
\end{tabular}

** Significant at 1\% level of significance

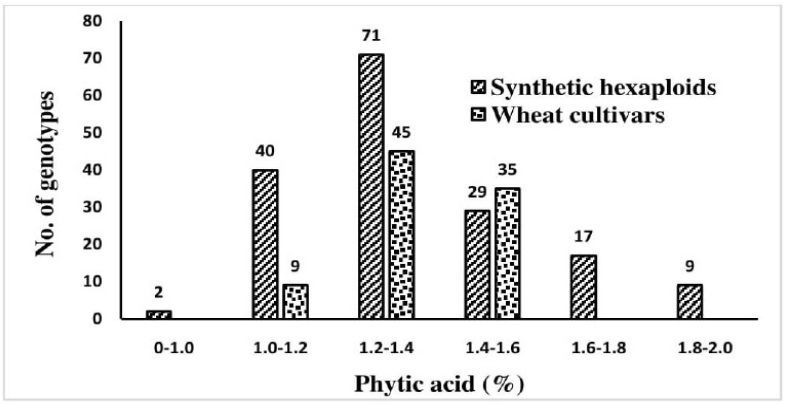

Fig. 1 Levels of phytic acid in the grains of synthetic hexaploids and wheat cultivars released in India indicating larger variability in synthetic hexaploids as compared to wheat cultivars
3.2 Variations in phytase levels: Higher phytase levels are important in increasing micronutrient bio-availability (Lopez et al., 2003) by degrading phytic acid and thus releasing more micronutrients in human intestine. There were 4.1 fold differences in varieties developed in India and 7.9 fold variations in synthetic hexaploids (Fig. 2). It varied from 284 to $1155 \mathrm{FTU} / \mathrm{Kg}$ with the mean value of $516 \mathrm{FTU} / \mathrm{Kg}$ in released varieties and from 255 to $2025 \mathrm{FTU} / \mathrm{Kg}$ with the mean value of $751 \mathrm{FTU} / \mathrm{Kg}$ in synthetic hexaploids. It is interesting to note that greater variability was observed in synthetic hexaploids. Similar variations were reported by Ram et al., 2010 in a set of wheat germplasm. In this investigation more numbers of synthetic hexaploids and new wheat cultivars were used for estimation of phytase levels. Large diversity in phytase levels in synthetic hexaploids may be because of the fact that synthetics were developed by crossing different species of tetraploids with different accessions of Ae. tauschii. Because of smaller number of hybridization events and the restricted geographic origin of these events, most of the variations were not tapped during the evolution of wheat by natural crossing between Ae. tauschii and tetraploid wheat. This might have led to narrow genetic diversity for bread wheat (Talbert et al., 1998). The analysis of variance showed significant differences among genotypes for phytase levels and thus great possibility of genetic improvement in wheat for high phytase levels(Table 2).

Table 2. Analysis of variance (ANOVA) of phytase activity in the grains of 168 synthetic hexaploids

\begin{tabular}{lllll}
\hline Source & SS & df & MS & F \\
\hline Genotypes & 60919574 & 167 & 167 & $32.91^{* *}$ \\
Replication & 90731.17 & 2 & 2 & 8.18 \\
Error & 1851054 & 167 & 167 & \\
Total & 62861359 & 336 & 336 & \\
\hline
\end{tabular}

** Significant at 1\% level of significance

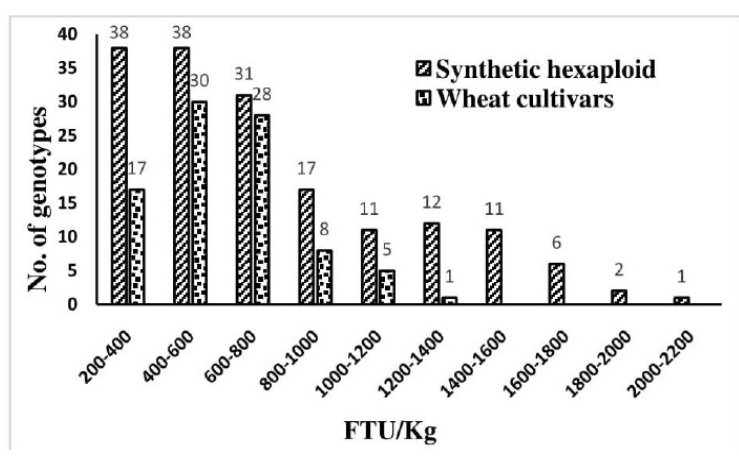

Fig. 2 Frequency distribution of phytase levels in the grains of 168 synthetic hexaploid and 89 wheat cultivars indicating larger variability in synthetic hexaploids as compared to wheat cultivars 
3.3 Testing the robustness of the methodology of estimating phytase levels : Some of the earlier reports (Dost and Tokul, 2006; Steiner et al., 2007; Ficco et al., 2009) indicated a diverse range of phytase levels due to differences in the protocol of phytase assay. Earlier, Ram et al. (2010), made comparison of three different methods. In this report we used direct assay method of Ram et al. (2010) and validated the robustness of the assay. There was very strong correlation $\left(\mathrm{R}^{2}=0.89\right)$ in readings of duplicate samples of the wheat flours (Fig. 3). This demonstrated that the direct assay method is more suitable for phytase analysis as it gives both reproducibility and repeatability of results. It has additional advantage of being taking lesser time and cost in the analysis. Moreover, $100 \mathrm{mg}$ of the whole meal flour sample used in the evaluation of phytase levels has the advantage of analyzing small quantity of materials available in the segregating generations of breeding programme.

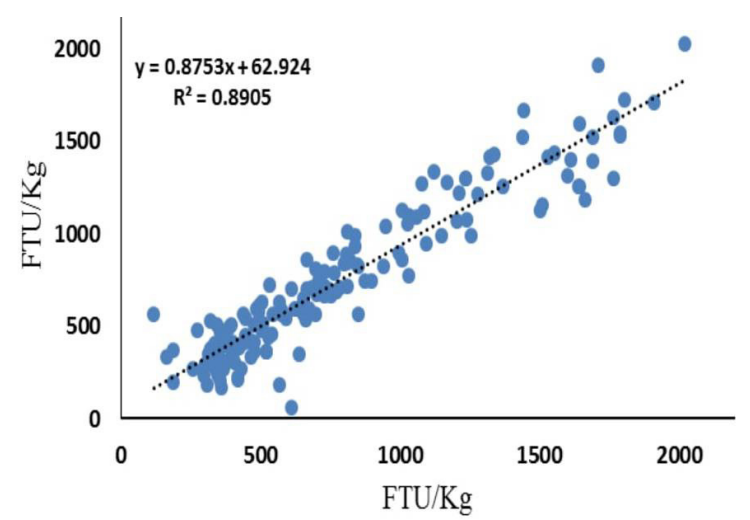

Fig. 3 Relationship between phytase levels estimated in duplicate samples using direct assay method indicating the high repeatability of the assay

\subsection{Improvement of phytase levels in the background of $P B W$} 343: One of the synthetic hexaploids (Syn70) exhibiting higher phytase levels was utilized in making crosses with PBW 343 for enhancing phytase levels in this cultivar. Phytase levels were $610 \mathrm{FTU} / \mathrm{kg}$ and $1450 \mathrm{FTU} / \mathrm{kg}$ in PBW 343 and synthetic hexaploid 70, respectively. The cross was advanced to $\mathrm{BC}_{2} \mathrm{~F}_{4}$ level during 2016-17 and desirable segregants for high phytase levels were selected based on microlevel test validated in this investigation. Phytase level varied from $570 \mathrm{FTU} / \mathrm{kg}$ to $1569 \mathrm{FTU} / \mathrm{kg}$ in the backcross population (Fig. 4). Desirable segregants with high yield potential and high phytase levels will be further advanced and selected for yield trials for identification of superior cultivar. The data clearly demonstrated that synthetic hexaploids can be used to enhance and diversify phytase levels in bread wheat for improving nutritional quality of wheat for enhanced bio-availability of micronutrients.

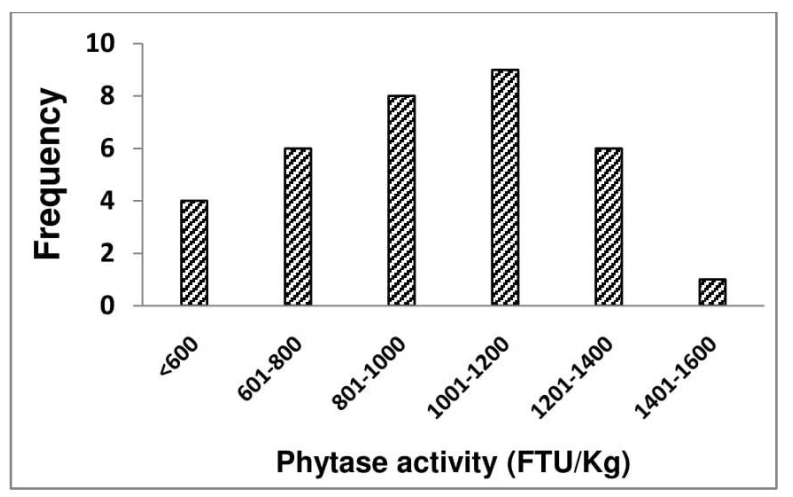

Fig. 4 Phytase levels in $\mathrm{BC}_{2} \mathrm{~F}_{4}$ population of a cross between PBW 343 and Synthetic 70 indicating enhanced phytase levels in advanced lines

Large variations were observed for both phytic acid and phytase levels among synthetic hexaploids and bread wheat genotypes. The data demonstrated direct assay method of phytase activity using $100 \mathrm{mg}$ of the flour has high reproducibility with the advantage of analysing large segregating generations of breeding programme. The study also demonstrated that synthetic hexaploids having high phytase levels are useful source for the improving phytase levels in bread wheat cultivars.

\section{Acknowledgement}

Authors are highly grateful to ICAR-IIWBR, Karnal, India for providing facilities to carry outthe research work under the institute project No. CRSCIIWBRSIL201503000174.

\section{References}

1. Brinch-Pedersen H, LD Sorensen and PB Holm. 2002. Engineering crop plants: getting a handle on phosphate. Trends in Plant Science 7:118-125.

2. Dost K and O Tokul. 2006. Determination of phytic acid in wheat and wheat products by reverse phase high performance liquid chromatography. Analytica Chimica Acta 558:22-27.

3. Ficco DBM, C Riefolo, G Nicastro, VD Simone, AMD Gesu, R Beleggia, C Platani, L Cattivelli and P De Vita. 2009. Phytate and mineral elements 
concentration in a collection of Italian wheat cultivars. Field Crops Research 111:235-242.

4. Gao Y, C Shang, MA Saghai Maroof, RM Biyashev, EA Grabau, P Kwanyuen, JW Burton and GR Buss. 2007. A modified colorimetric method for phytic acid analysis in soybean. Crop Science 47:1797-1803.

5. Greiner R and U Konietzny. 2006. Phytase for food application. Food Technology and Biotechnology 44(2): 125-140.

6. Guo Z, P Xu, Z Zhang and Y Guo. 2012. Segregation ratios of colored grains in F1 hybrid wheat. Crop Breeding and Applied Biotechnology 12:126-131.

7. Kim JC, BP Mullan, PH Selle and JR Pluske. 2002. Levels of total phosphorus, phytate phosphorus and phytase activity in three varieties of Western Australian wheat in response to growing region, growing season and storage. Australian Journal of Agricultural Research 53:1361-1366.

8. Kim TW and XG Lei. 2005. An improved method for rapid determination of phytase activity in animal feed. Journal of Animal Science 83:1062-1067.

9. Liu ZH, HY Wang, XE Wang, GP Zhang, PD Chen and DJ Liu. 2007. Phytase activity, phytate, iron, and zinc contents in wheat pearling fractions and their variation across production locations. Journal of Cereal Science 45:319-326.

10. Lopez HW, VKrespine, ALemaire, C Coudray, CF Coudray, A Messager, C Demigne and C Remesy. 2003. Wheat variety has a major influence on mineral bioavailability; studies in rats. Journal of Cereal Science 37:257-266.

11. Lorenz AJ, MP Scott and KR Lamkey. 2007. Quantitative determination of phytate and inorganic phosphorus for maize breeding. Crop Science 47:598604 .
12. Okot-Kotber M, KJ Yong, KBagorogoza and A Liavoga. 2003. Phytase activity in extracts of flour and bran from wheat cultivars: enhanced extractability with $B$-glucanase and endo-xylanase. Journal of Cereal Science 38:307-315.

13. PiironenV, AMLampi, PEkholm, MSMarttila and KH Liukkonen. 2009. Micronutrients and phytochemicals in wheat grain. In: Khan K, PR Shewry. (Eds.), Wheat Chemistry and Technology. AACC International, Minnesota, pp. 401-435.

14. Ram S, A Verma and S Sharma. 2010. Large variability exists in phytase levels among Indian wheat varieties and synthetic hexaploids. Journal of Cereal Science 52:486-490.

15. Sandberg AS and H Andersson. 1988. Effect of dietary phytase on the digestion of phytate in the stomach and small intestines of humans. Journal of Nutrition 118: 469-473.

16. Steiner T, R Mosenthin, B Zimmermann, R Greiner and SRoth. 2007. Distribution of phytase activity, total phosphorus and phytate phosphorus in legume seeds, cereals and cereal by-products as influenced by harvest year and cultivar animal. Feed Science and Technology 133(3):320-334.

17. Talbert LE, LY Smith and NK Blake. 1998. More than one origin of hexaploid wheat is indicated by sequence comparison of lowcopy DNA. Genome 41:402-407.

18. Ullah AHJ 1988. Production, rapid purification and catalytic characterization of extracellular phytase from Aspergillus ficcum. Preparatory Biochemistry 18:443458. 